\title{
Single cell oils of the cold-adapted oleaginous yeast Rhodotorula glacialis DBVPG 4785
}

\author{
Alberto Amaretti, Stefano Raimondi, Maurizio Sala, Lucia Roncaglia, Marzia De Lucia, Alan Leonardi, \\ Maddalena Rossi ${ }^{*}$
}

\begin{abstract}
Background: The production of microbial lipids has attracted considerable interest during the past decade since they can be successfully used to produce biodiesel by catalyzed transesterification with short chain alcohols. Certain yeast species, including several psychrophilic isolates, are oleaginous and accumulate lipids from 20 to $70 \%$ of biomass under appropriate cultivation conditions. Among them, Rhodotorula glacialis is a psychrophilic basidiomycetous species capable to accumulate intracellular lipids.

Results: Rhodotorula glacialis DBVPG 4785 is an oleaginous psychrophilic yeast isolated from a glacial environment. Despite its origin, the strain abundantly grew and accumulated lipids between -3 to $20^{\circ} \mathrm{C}$. The temperature did not influence the yield coefficients of both biomass and lipids production, but had positive effect on the growth rate and thus on volumetric productivity of lipid. In glucose-based media, cellular multiplication occurred first, while the lipogenic phase followed whenever the culture was limited by a nutrient other than glucose. The extent of the carbon excess had positive effects on triacylglycerols production, that was maximum with $120 \mathrm{~g} \mathrm{~L}^{-1}$ glucose, in terms of lipid concentration (19 $\mathrm{g} \mathrm{L}^{-1}$ ), lipid/biomass (68\%) and lipid/glucose yields (16\%). Both glucose concentration and growth temperature influenced the composition of fatty acids, whose unsaturation degree decreased when the temperature or glucose excess increased.

Conclusions: This study is the first proposed biotechnological application for Rhodotorula glacialis species, whose oleaginous biomass accumulates high amounts of lipids within a wide range of temperatures through appropriate cultivation C:N ratio. Although R. glacialis DBVPG 4785 is a cold adapted yeast, lipid production occurs over a broad range of temperatures and it can be considered an interesting microorganism for the production of single cell oils.
\end{abstract}

\section{Background}

Oleaginous microorganisms, such as yeasts, fungi, and microalgae, can accumulate high amounts of neutral storage lipids under appropriate cultivation conditions $[1,2]$, therefore their potential as sources of triacylglycerols (TAG) has attracted considerable attention. The utilization of microbial TAG has been increasingly explored during the past decade in the biofuels industry [3]. Microbial lipids can be successfully used to produce biodiesel by catalyzed transesterification with short chain alcohols, although they have not been industrially exploited until now $[4,5]$. Plant oils are the major feedstock for biodiesel production but encounter limitations regarding their availability at competitive price. These

\footnotetext{
* Correspondence: maddalena.rossi@unimore.it

Department of Chemistry-University of Modena and Reggio Emilia, via Campi 183, 41100 Modena, Italy
}

drawbacks decreases the attractiveness of biodiesel as a competitive alternative to petroleum-based fuel. The microbial production of lipids promises to overcome these limitations. In fact, the exploitation of microbial systems to produce lipids from cheap carbon sources has many advantages, including short life cycle, low affection by venue, season and climate, and possibility of process scale-up [4].

Many yeast species were found to be oleaginous and accumulated TAG from 20 to $70 \%$ of biomass under appropriate cultivation conditions. They include Cryptococcus albidus, Lipomyces lipofera, Lipomyces starkeyi, Rhodosporidium toruloides, Rhodotorula glutinis, Trichosporon pullulan, and Yarrowia lipolytica $[2,6,7]$. Lipid accumulation in oleaginous yeasts and molds has been demonstrated to occur when a nutrient in the medium (e.g. the nitrogen or the phosphorus source)

\section{Biomed Central}


becomes limited and the carbon source is present in excess. Nitrogen limitation is the most efficient condition for inducing lipogenesis. During the growth phase, nitrogen is necessary for the synthesis of proteins and nucleic acids, while the carbon flux is distributed among energetic and anabolic processes yielding carbohydrates, lipids, nucleic acids and proteins. When nitrogen gets limited, the growth rate slows down and the synthesis of proteins and nucleic acids tends to cease. In non-oleaginous species, the carbon excess remains unutilized or is converted into storage polysaccharides, while, in oleaginous species, it is preferentially channeled toward lipid synthesis, leading to the accumulation of TAG within intracellular lipid bodies $[6,8]$.

Psychrophilic yeasts are understudied sources of biodiversity, which can play a novel role in biotechnology, thus offering an alternative to conventional microorganisms. Our previous work demonstrated that several cold-adapted yeasts can be regarded as excellent lipid producers [9]. Nonetheless, neither has the lipogenesis in psychrophilic yeasts been studied, nor have culture strategies been developed in order to improve TAG production, in the perspective of a potential utilization in biofuel industry. In the present work, the lipid composition and accumulation by the cold adapted yeast Rhodotorula glacialis DBVPG 4785 was investigated within a wide range of temperatures and carbon/nitrogen ratios. The strain belongs to a recently described psychrophilic basidiomycetous species, containing diverse yeast isolates from glacial environments [10,11], and has been demonstrated to accumulate intracellular lipids [9]. To our knowledge, this is the unique study that investigate microbial lipids production by $R$. glacialis, with the aim to develop a novel potential alternative feedstock for biodiesel industry.

\section{Results and Discussion}

Growth and lipid production at different temperatures Rhodotorula glacialis DBVPG 4785 was cultured batchwise at different temperatures from -3 to $25^{\circ} \mathrm{C}$ in a medium containing $40 \mathrm{~g} \mathrm{~L}^{-1}$ glucose. This cold adapted strain, which was isolated from an alpine glacial environment, grew at zero and sub-zero temperatures, but abundant growth was observed up to $20^{\circ} \mathrm{C}$, although it did not occur at $25^{\circ} \mathrm{C}$. Therefore, $R$. glacialis DBVPG 4785 can be regarded as an obligate psychrophilic strain, based on the current classification [12,13].

In the range of temperature allowing growth, the microorganism always consumed the carbon source completely. On the average, $14.1 \mathrm{~g} \mathrm{~L}^{-1}$ dry biomass and $4.8 \mathrm{~g} \mathrm{~L}^{-1}$ lipids were obtained from $40 \mathrm{~g} \mathrm{~L}^{-1}$ glucose, without any significant effect $(\mathrm{P}>0.05)$ of temperature (Table 1). Thus, the acclimation to different temperature did not affect biomass/substrate $\left(\mathrm{Y}_{\mathrm{X} / \mathrm{S}}=0.35 \mathrm{~g} \mathrm{~g}^{-1}\right)$, lipid/biomass $\left(\mathrm{Y}_{\mathrm{L} / \mathrm{X}}=0.34 \mathrm{~g} \mathrm{~g}^{-1}\right)$, and lipid/glucose $\left(\mathrm{Y}_{\mathrm{L} / \mathrm{S}}=0.12 \mathrm{~g} \mathrm{~g}^{-1}\right)$ yield coefficients $(\mathrm{P}>0.05)$.

As expected, the temperature markedly affected the specific growth rate $(\mu)$. The $\mu$ increased if the temperature raised, was the highest at $15^{\circ} \mathrm{C}\left(0.075 \mathrm{~h}^{-1}\right)$, then declined at $20^{\circ} \mathrm{C}$ (Table 1). As a result, volumetric productivities of both biomass $\left(\mathrm{Q}_{\mathrm{X}}\right)$ and lipids $\left(\mathrm{Q}_{\mathrm{L}}\right)$ depended by the temperature and were maximum at $15^{\circ}$ $\mathrm{C}$ (0.101 and $0.034 \mathrm{~g} \mathrm{~L}^{-1} \mathrm{~h}^{-1}$, respectively).

\section{Effects of temperature on fatty acids composition}

The fatty acids (FA) with chain length ranging from 14 to 18 carbons, including their saturated (SFA), monounsaturated (MUFA), and poly-unsaturated (PUFA) forms, dominated the FA profile of $R$. glacialis DBVPG 4785, always accounting for more than 99\% (Table 2). Eighteen-carbons FA were the most abundant (69.0 to $83.1 \%)$, followed by sixteen-carbons FA (14.0 to $27.6 \%$ ). Myristic acid (C14) was approximately $3 \%$ at all the temperatures (Table 2), lauric acid (C12) was always found in traces, and the FA with 20 carbons or more were negligible. The most abundant unsaturated FA were palmitoleic $\left(\mathrm{C} 16: 1 \Delta^{9}\right)$, oleic $\left(\mathrm{C} 18: 1 \Delta^{9}\right)$, linoleic $\left(\mathrm{C} 18: 2 \Delta^{9,12}\right)$, and $\alpha$-linolenic $\left(\mathrm{C} 18: 3 \Delta^{9,12,15}\right)$ acids. Other unsaturated FA were negligible, with the sole exception of $\gamma$-linolenic $\left(\mathrm{C} 18: 3 \Delta^{6,9,12}\right)$ and stearidonic acid $\left(\mathrm{C} 18: 4 \Delta^{6,9,12,15}\right)$ which were found in low amounts at 0 and $-3^{\circ} \mathrm{C}(<0.4 \%$ in sum $)$ and were likely produced through $\Delta 6$ desaturase. Although stearidonic acid is known as an intermediate in the conversion of $\alpha$-linolenic acid to eicosapentaenoic acid and docosahexaenoic acid $[6,14]$, long-chain highly-unsaturated FA were absent.

To regulate membrane fluidity and functionality at low temperatures, $R$. glacialis DBVPG 4785 exploited diverse changes in lipid composition, consisting in the increased degree of unsaturation, herein described by the quantitative descriptor UI (unsaturation index), and the incorporation of higher amounts of 18-carbons FA at the expenses of the 16-carbons ones (Table 2). The relative abundance of SFA diminished from 36.9 to $18.6 \%$ if the temperature decreased from 20 to $0^{\circ} \mathrm{C}$, due to the decrease of both palmitic and stearic acids $(\mathrm{P} \leq 0.05)$. The opposite trend was observed for both linoleic and $\alpha$-linolenic acids $(P \leq 0.05)$, which were the major responsible for the increase of the UI $(\mathrm{P} \leq$ $0.05)$. The production of 18-carbons FA seems to be an adaptive feature of the yeasts coming from cold environments, and may be due to the necessity to elongate FA beyond C16 in order to introduce additional double bonds by $\Delta 12$ and $\Delta 15$ desaturases [9]. The relative amount of palmitoleic acid slightly increased with temperature, but never accounted for more than $2.1 \%$. 
Table 1 Effects of the growth temperature on growth and lipid production of $R$. glacialis DBVPG 4785

\begin{tabular}{|c|c|c|c|c|c|c|c|c|}
\hline $\begin{array}{c}\mathrm{T} \\
\left({ }^{\circ} \mathrm{C}\right)\end{array}$ & $\underset{\left(h^{-1}\right)}{\mu}$ & $\begin{array}{c}Y_{L / S} \\
\left(g^{-1}\right)\end{array}$ & $\begin{array}{c}Y_{\mathrm{L} / \mathrm{X}} \\
\left(\mathrm{g} \mathrm{g}^{-1}\right)\end{array}$ & $\begin{array}{c}Y_{X / S} \\
\left(\mathrm{~g} \mathrm{~g}^{-1}\right)\end{array}$ & $\begin{array}{c}Q_{x} \\
\left(g^{-1} h^{-1}\right)\end{array}$ & $\begin{array}{c}\mathrm{Q}_{\mathrm{L}} \\
\left(\mathrm{g} \mathrm{L}^{-1} \mathrm{~h}^{-1}\right)\end{array}$ & $\begin{array}{c}\text { Biomass } \\
\left(\mathrm{g} \mathrm{L}^{-1}\right)\end{array}$ & $\begin{array}{l}\text { Lipids } \\
\left(\mathrm{g} \mathrm{L}^{-1}\right)\end{array}$ \\
\hline-3 & $0.010^{d}$ & $0.12^{\mathrm{a}}$ & $0.35^{a}$ & $0.33^{\mathrm{a}}$ & $0.015^{\mathrm{e}}$ & $0.005^{d}$ & $13.3^{\mathrm{a}}$ & $4.6^{\mathrm{a}}$ \\
\hline 0 & $0.019^{d}$ & $0.13^{\mathrm{a}}$ & $0.35^{\mathrm{a}}$ & $0.36^{\mathrm{a}}$ & $0.023^{d}$ & $0.007^{d}$ & $14.4^{\mathrm{a}}$ & $5.1^{\mathrm{a}}$ \\
\hline 5 & $0.053^{c}$ & $0.12^{\mathrm{a}}$ & $0.32^{\mathrm{a}}$ & $0.36^{\mathrm{a}}$ & $0.050^{c}$ & $0.016^{c}$ & $14.3^{\mathrm{a}}$ & $4.7^{\mathrm{a}}$ \\
\hline 10 & $0.071^{\mathrm{a}}$ & $0.12^{\mathrm{a}}$ & $0.34^{a}$ & $0.35^{\mathrm{a}}$ & $0.077^{b}$ & $0.026^{b}$ & $14.0^{\mathrm{a}}$ & $4.8^{\mathrm{a}}$ \\
\hline 15 & $0.075^{a}$ & $0.12^{\mathrm{a}}$ & $0.32^{\mathrm{a}}$ & $0.36^{a}$ & $0.101^{a}$ & $0.034^{a}$ & $14.3^{\mathrm{a}}$ & $4.7^{\mathrm{a}}$ \\
\hline 20 & $0.068^{b}$ & $0.12^{\mathrm{a}}$ & $0.35^{\mathrm{a}}$ & $0.35^{\mathrm{a}}$ & $0.075^{b}$ & $0.023^{b}$ & $14.2^{\mathrm{a}}$ & $5.0^{\mathrm{a}}$ \\
\hline
\end{tabular}

The strain was cultured at different temperatures in GMY medium containing $40 \mathrm{~g} \mathrm{~L}^{-1}$ glucose, as described in Methods section. The final concentration of biomass and lipids, the specific growth rate $(\mu)$, the biomass/glucose, lipid/glucose, and lipid/biomass yield coefficients $\left(Y_{X / S}, Y_{L / S}\right.$, and $Y_{L / X}$, respectively), and the volumetric productivities of biomass and lipids $\left(\mathrm{Q}_{X}\right.$ and $\mathrm{Q}_{\mathrm{L}}$, respectively) are reported as a function of the growth temperature. The values are means of three independent experiments. Within a column, superscripts indicate statistically similar means, $\mathrm{P}>0.05, \mathrm{n}=3$.

At $-3^{\circ} \mathrm{C}$, the FA profile differed from the trend described above, especially due to the diverse distribution within the $\mathrm{C} 18$ series. The lipid extract was richer in C18, C18:1, and C18:3, while a lower amount of C18:2 was observed. The occurrence of a remarkably high amount of $\mathrm{C} 18: 3$ may arise from the $\mathrm{NaCl}$ supplementation to prevent freezing, since salinity has been demonstrated to improve membrane fluidity in certain yeasts through the incorporation of FA with higher unsaturation $[15,16]$.

\section{Effects of glucose concentration on growth and lipid production}

Most of oleaginous yeasts accumulate storage lipids when a nutrient becomes exhausted but the carbon source is still available and continues to be assimilated by the cells which progressively become obese $[1,17,18]$. To investigate whether lipid production by $R$. glacialis DBVPG 4785 can be improved through a proper nutrient limitation, the strain was cultured at $10^{\circ} \mathrm{C}$ with the following initial glucose concentrations: $1.6,4,8,16,40,80,120$, and $160 \mathrm{~g} \mathrm{~L}^{-1}$. Since the yeast extract contained $8 \%(\mathrm{w} / \mathrm{w})$ nitrogen (data not shown), the corresponding C:N ratios were $5.6,8.5,13,23,52,101,149$, and 198, respectively.
For initial glucose ranging from 1.6 to $40 \mathrm{~g} \mathrm{~L}^{-1}$, the exponential growth occurred with the same specific rate $(\mu)$ of $0.071 \mathrm{~h}^{-1}$, which decreased with higher initial glucose concentration (Table 3).

In the range between 1.6 and $8 \mathrm{~g} \mathrm{~L}^{-1}$ glucose, the culture was carbon limited and entered into stationary phase in correspondence with glucose exhaustion. Intracellular lipids were scarce, accounting for less than $10 \%$ of biomass (Table 3).

Nutrients were nearly balanced with $16 \mathrm{~g} \mathrm{~L}^{-1}$ glucose, whereas the culture was limited by a nutrient other than the carbon source at higher concentrations. In these conditions growth and lipid production occurred through two stages (Fig. 1). At the end of the growth phase $(72 \mathrm{~h})$, approximately $16 \mathrm{~g} \mathrm{~L}^{-1}$ glucose were consumed and lipids were the $20 \%$ of biomass. Lipid production occurred mostly afterwards, consuming the glucose still available at the rate of $0.34 \mathrm{~g} \mathrm{~L}^{-1} \mathrm{~h}^{-1}$ without any relation to the initial concentration, even though the rate gradually decreased. The carbon source was always exhausted for initial glucose concentrations up to $120 \mathrm{~g} \mathrm{~L}^{-1}$. Cells did not multiply during the lipogenic phase, while biomass dry weight augmented in proportion to glucose consumption because of the accumulation of intracellular

Table 2 Effects of the growth temperature on fatty acids (FA) composition

\begin{tabular}{|c|c|c|c|c|c|c|c|c|c|c|c|c|c|}
\hline \multirow{2}{*}{$\begin{array}{c}\mathrm{T} \\
\left({ }^{\circ} \mathrm{C}\right)\end{array}$} & \multicolumn{12}{|c|}{ Relative abundance of FA (w/w\%) } & \multirow[t]{2}{*}{$\mathrm{UI}$} \\
\hline & C14 & C16 & C16:1 & C18 & C18:1 & C18:2 & C18:3 & $\begin{array}{c}\text { Total } \\
\text { C16 }\end{array}$ & $\begin{array}{c}\text { Total } \\
\text { C18 }\end{array}$ & $\begin{array}{c}\text { Total } \\
\text { SFA }\end{array}$ & $\begin{array}{r}\text { Total } \\
\text { MUFA }\end{array}$ & $\begin{array}{l}\text { Total } \\
\text { PUFA }\end{array}$ & \\
\hline-3 & $3.4^{\mathrm{a}}$ & $14.6^{\mathrm{bc}}$ & $1.3^{\mathrm{a}}$ & $5.6^{b}$ & $35.6^{\mathrm{a}}$ & $26.0^{d}$ & $13.5^{\mathrm{a}}$ & $15.9^{\mathrm{bc}}$ & $80.7^{b}$ & $23.6^{c}$ & $36.9^{a}$ & $39.5^{c}$ & $1.29^{\mathrm{b}}$ \\
\hline 0 & $2.9^{\mathrm{a}}$ & $13.0^{c}$ & $1.0^{\mathrm{a}}$ & $2.7^{c}$ & $25.1^{c}$ & $48.5^{\mathrm{a}}$ & $6.9^{b}$ & $14.0^{c}$ & $83.1^{\mathrm{a}}$ & $18.6^{d}$ & $26.1^{c}$ & $55.4^{\mathrm{a}}$ & $1.44^{\mathrm{a}}$ \\
\hline 5 & $3.0^{\mathrm{a}}$ & $15.5^{\mathrm{b}}$ & $1.2^{\mathrm{a}}$ & $4.7^{b}$ & $27.8^{\mathrm{b}}$ & $43.0^{\mathrm{b}}$ & $4.8^{c}$ & $16.7^{\mathrm{b}}$ & $80.3^{b}$ & $23.2^{c}$ & $29.0^{\mathrm{b}}$ & $47.8^{\mathrm{b}}$ & $1.29^{\mathrm{b}}$ \\
\hline 10 & $3.2^{\mathrm{a}}$ & $16.0^{\mathrm{b}}$ & $1.6^{\mathrm{a}}$ & $5.2^{b}$ & $28.6^{\mathrm{b}}$ & $41.0^{c}$ & $4.4^{c}$ & $17.6^{\mathrm{b}}$ & $79.2^{\mathrm{b}}$ & $24.4^{c}$ & $30.2^{b}$ & $45.4^{\mathrm{b}}$ & $1.26^{\mathrm{b}}$ \\
\hline 15 & $2.6^{\mathrm{a}}$ & $24.6^{\mathrm{a}}$ & $2.1^{\mathrm{a}}$ & $5.6^{b}$ & $23.6^{c}$ & $39.4^{c}$ & $2.1^{d}$ & $26.7^{\mathrm{a}}$ & $70.7^{c}$ & $32.8^{\mathrm{b}}$ & $25.7^{c}$ & $41.5^{c}$ & $1.11^{c}$ \\
\hline 20 & $3.4^{\mathrm{a}}$ & $25.7^{\mathrm{a}}$ & $1.9^{\mathrm{a}}$ & $7.8^{\mathrm{a}}$ & $20.6^{d}$ & $39.2^{c}$ & $1.4^{\mathrm{d}}$ & $27.6^{\mathrm{a}}$ & $69.0^{c}$ & $36.9^{\mathrm{a}}$ & $22.5^{d}$ & $40.6^{c}$ & $1.05^{c}$ \\
\hline
\end{tabular}

R. glacialis DBVPG 4785 was cultured at different temperatures in GMY medium containing $40 \mathrm{~g} \mathrm{~L}^{-1}$ glucose. FA within the lipid extract were transformed into the corresponding methyl-esters and were analyzed as described in Methods section. The relative abundance of each FA, the sum of 16- and 18-carbons FA, the sum of the saturated, mono-unsaturated, and poly-unsaturated ones (SFA, MUFA, and PUFA, respectively), and the unsaturation index (UI) are reported as a function of the growth temperature. The values are means of three independent experiments. Within a column, superscripts indicate statistically similar means, $\mathrm{P}>0.05$, $\mathrm{n}=3$. 
Table 3 Effects of glucose concentration on growth and lipid production of $R$. glacialis DBVPG 4785

\begin{tabular}{|c|c|c|c|c|c|c|c|c|c|c|}
\hline $\begin{array}{c}\text { Glucose } \\
\left(\mathrm{g} \mathrm{L}^{-1}\right)\end{array}$ & $\underset{\left(h^{-1}\right)}{\mu}$ & $\begin{array}{c}Y_{\mathrm{L} / \mathrm{S}} \\
\left(\mathrm{g} \mathrm{g}^{-1}\right)\end{array}$ & $\begin{array}{c}Y_{\mathrm{L} / \mathrm{X}} \\
\left(\mathrm{g} \mathrm{g}^{-1}\right)\end{array}$ & $\begin{array}{c}Y_{\mathrm{X} / \mathrm{s}} \\
\left(\mathrm{g} \mathrm{g}^{-1}\right)\end{array}$ & $\begin{array}{c}\mathrm{Q}_{\mathrm{X}} \\
\left(\mathrm{g} \mathrm{L}^{-1} \mathrm{~h}^{-1}\right)\end{array}$ & $\left(g_{\mathrm{L}^{-1}}^{\mathrm{Q}_{\mathrm{L}}} \mathrm{h}^{-1}\right)$ & $\begin{array}{l}\text { Cells } \\
\left(\mathrm{ml}^{-1}\right)\end{array}$ & $\begin{array}{c}\text { Biomass } \\
\left(\mathrm{g} \mathrm{L}^{-1}\right)\end{array}$ & $\begin{array}{c}\text { Carbohydrates } \\
\left(\mathrm{g} \mathrm{L}^{-1}\right)\end{array}$ & $\begin{array}{l}\text { Lipids } \\
\left(\mathrm{g} \mathrm{L}^{-1}\right)\end{array}$ \\
\hline 1.6 & $0.070^{a}$ & $0.07^{d}$ & $0.06^{\mathrm{e}}$ & $1.31^{a}$ & $0.045^{e}$ & $0.0030^{f}$ & $1.2 \mathrm{e}+08^{c}$ & $2.1^{\mathrm{h}}$ & $0.1^{f}$ & $0.12^{9}$ \\
\hline 4 & $0.071^{\mathrm{a}}$ & $0.05^{d}$ & $0.05^{e}$ & $0.94^{b}$ & $0.052^{d}$ & $0.0026^{f}$ & $3.5 e+08^{b}$ & $3.8^{\mathrm{g}}$ & $0.3^{e}$ & $0.19^{9}$ \\
\hline 8 & $0.070^{\mathrm{a}}$ & $0.05^{d}$ & $0.09^{e}$ & $0.61^{c}$ & $0.052^{d}$ & $0.0044^{e}$ & $4.0 e+08^{a b}$ & $4.9^{f}$ & $0.8^{\mathrm{d}}$ & $0.42^{f}$ \\
\hline 16 & $0.072^{\mathrm{a}}$ & $0.09^{c}$ & $0.20^{d}$ & $0.44^{d}$ & $0.056^{c}$ & $0.011^{d}$ & $4.2 \mathrm{e}+08^{\mathrm{a}}$ & $7.0^{\mathrm{e}}$ & $1.6^{\mathrm{C}}$ & $1.36^{\mathrm{e}}$ \\
\hline 40 & $0.072^{\mathrm{a}}$ & $0.12^{b}$ & $0.34^{c}$ & $0.35^{\mathrm{e}}$ & $0.075^{b}$ & $0.025^{c}$ & $4.5 \mathrm{e}+08^{\mathrm{a}}$ & $14^{d}$ & $3.7^{b}$ & $4.74^{d}$ \\
\hline 80 & $0.065^{b}$ & $0.15^{\mathrm{a}}$ & $0.55^{\mathrm{b}}$ & $0.28^{f}$ & $0.076^{b}$ & $0.042^{b}$ & $4.4 \mathrm{e}+08^{\mathrm{a}}$ & $22^{c}$ & $5.4^{\mathrm{a}}$ & $12^{c}$ \\
\hline 120 & $0.060^{b c}$ & $0.16^{\mathrm{a}}$ & $0.68^{\mathrm{ba}}$ & $0.23^{9}$ & $0.079^{a}$ & $0.054^{a}$ & $4.3 e+08^{a}$ & $28^{\mathrm{b}}$ & $4.8^{\mathrm{a}}$ & $19^{b}$ \\
\hline 160 & $0.057^{c}$ & $0.16^{\mathrm{a}}$ & $0.68^{\mathrm{ba}}$ & $0.23^{9}$ & $0.080^{a}$ & $0.054^{\mathrm{a}}$ & $4.4 \mathrm{e}+08^{\mathrm{a}}$ & $33^{a}$ & $5.0^{\mathrm{a}}$ & $22^{\mathrm{a}}$ \\
\hline
\end{tabular}

The strain was cultured at $10^{\circ} \mathrm{C}$ in GMY medium containing different glucose concentration, as described in Methods section. The final concentration of biomass,

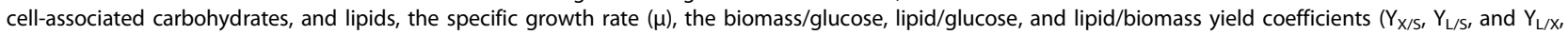
respectively), and the volumetric productivities of biomass and lipids $\left(Q_{X}\right.$ and $Q_{L}$, respectively) are reported as a function of initial glucose concentration. The values are means of three independent experiments. Within a column, superscripts indicate statistically similar means, $\mathrm{P}>0.05, \mathrm{n}=3$.

lipids (Fig. 1). The highest rate of lipid production was $0.080 \mathrm{~g} \mathrm{~L}^{-1} \mathrm{~h}^{-1}$, and gradually decreased along with the decrease of the glucose consumption rate.

With the increase of initial glucose concentration, final cell counts did not increase above $4.5 \mathrm{e}+08 \mathrm{ml}^{-1}$, while a more efficient conversion of glucose into lipids was achieved (Table 3). With 120 and $160 \mathrm{~g} \mathrm{~L}^{-1}$ glucose, the highest lipid production in terms of lipid concentration (19 and $22 \mathrm{~g} \mathrm{~L}^{-1}$, respectively), lipid content of biomass (68\%), lipid/glucose yield coefficient (16\%), and productivity $\left(0.054 \mathrm{~g} \mathrm{~L}^{-1} \mathrm{~h}^{-1}\right)$ was attained.

The lipid extract from a culture grown on $120 \mathrm{~g} \mathrm{~L}^{-1}$ glucose was subjected to ${ }^{1} \mathrm{H}$-NMR spectroscopy. The chemical shifts of all the signals were fitted to the spectra of TAG. In particular, the triplet pattern occurring in the spectrum region ranging from 2.20 and 2.45 ppm provided evidence confirming the absence of free FA [19].

The data herein reported confirmed that the extent of the carbon excess had largely positive effects on lipid

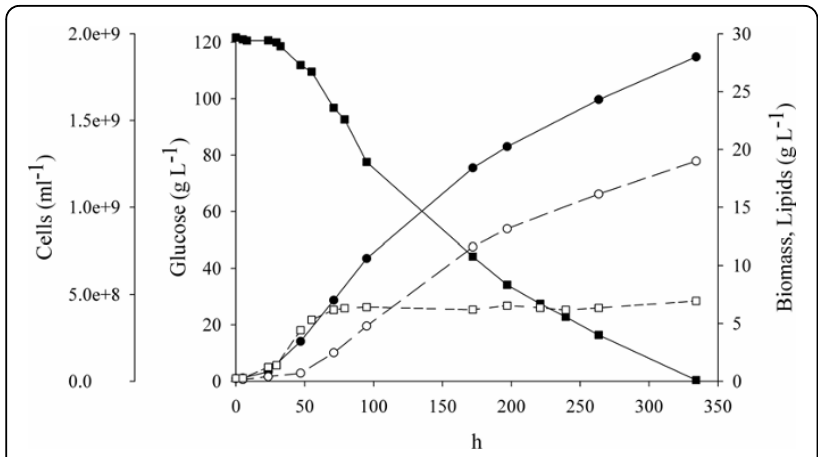

Figure 1 Timecourse of a batch culture of Rhodotorula glacialis DBVPG 4785. The strain was cultured at $10^{\circ} \mathrm{C}$ in GMY medium containing $120 \mathrm{~g} \mathrm{~L}^{-1}$ glucose. In these conditions, growth and lipid production occurred through two stages. The multiplication of cells took place first and finished when a nutrient other than the carbon source was exhausted, while lipid production occurred mostly afterwards. The black square, black circle, white square, and white circle represent glucose, biomass, cells counts, and lipids, respectively. production by $R$. glacialis DBVPG 4785 . Cell-associated carbohydrates were also positively affected by glucose. However, they became less abundant than lipids with the increase of glucose excess (Table 3), since the metabolism was preferentially channeled toward the accumulation of neutral lipids.

\section{Effects of glucose concentration on fatty acids composition}

R. glacialis DBVPG 4785 produced higher amounts of PUFA (e.g. C18:3) at the expenses of MUFA (e.g. C18:1) in carbon limited cultures compared with carbon excess conditions ( $\mathrm{P} \leq 0.05)$ (Table 4). Conversely, an excess of glucose increased MUFA and reduced PUFA.

In carbon limited cultures, the initial concentration of glucose did not influence the relative abundance of C18:3, C18:2, and C18:1. With the increase of the glucose concentration up to $16 \mathrm{~g} \mathrm{~L}^{-1}$ and more, the mean amount of C18:3 became much lower, the amount of C18:1 progressively augmented, and C18:2 diminished. As a consequence, the UI was higher $(\mathrm{P} \leq 0.05)$ under carbon limitation than in presence of glucose excess and further decreased with the increase of glucose concentration (Table 4).

These data corroborate the observation that in oleaginous yeasts and fungi the proportion of PUFA increases when nitrogen is in excess, while the rate of the desaturation reaction becomes low and the saturated fatty acids are not converted to PUFA with high carbon/ nitrogen ratios $[20,21]$.

\section{Conclusions}

This study explored the production of intracellular lipids by the psychrophilic oleaginous yeast Rhodotorula glacialis DBVPG 4785 as a function of the growth temperature and the $\mathrm{C}: \mathrm{N}$ ratio of the medium, with the aim to determine whether this strain could be exploited for biodiesel production. The strain is oleaginous and accumulates high amounts of lipids within the biomass when 
Table 4 Effects of glucose concentration on fatty acids (FA) composition

\begin{tabular}{|c|c|c|c|c|c|c|c|c|c|c|c|c|c|}
\hline \multirow{2}{*}{$\begin{array}{c}\text { Glucose } \\
\left(\mathrm{g} \mathrm{L}^{-1}\right)\end{array}$} & \multicolumn{12}{|c|}{ Relative abundance of FA ( $w / w \%)$} & \multirow[t]{2}{*}{$\mathrm{UI}$} \\
\hline & C14 & C16 & C16:1 & $\mathrm{C} 18$ & C18:1 & C18:2 & C18:3 & $\begin{array}{l}\text { Total } \\
\text { C16 }\end{array}$ & $\begin{array}{c}\text { Total } \\
\text { C18 }\end{array}$ & $\begin{array}{c}\text { Total } \\
\text { SFA }\end{array}$ & $\begin{array}{l}\text { Total } \\
\text { MUFA }\end{array}$ & $\begin{array}{l}\text { Total } \\
\text { PUFA }\end{array}$ & \\
\hline 1.6 & $3.1^{a}$ & $14.4^{\mathrm{a}}$ & $0.4^{a}$ & $7.4^{\mathrm{a}}$ & $4.3^{\mathrm{e}}$ & $43.8^{\mathrm{ab}}$ & $26.6^{a}$ & $14.8^{\mathrm{a}}$ & $82.1^{a}$ & $25.3^{\mathrm{a}}$ & $4.3^{f}$ & $70.4^{a}$ & $1.72^{\mathrm{a}}$ \\
\hline 4 & $3.1^{\mathrm{a}}$ & $15.1^{\mathrm{a}}$ & $1.1^{\mathrm{a}}$ & $7.2^{\mathrm{a}}$ & $6.3^{\text {de }}$ & $43.1^{\mathrm{ab}}$ & $24.1^{\mathrm{a}}$ & $16.2^{\mathrm{a}}$ & $80.7^{\mathrm{a}}$ & $25.4^{\mathrm{a}}$ & $7.4^{\mathrm{e}}$ & $67.2^{\mathrm{a}}$ & $1.66^{\mathrm{a}}$ \\
\hline 8 & $2.6^{a}$ & $13.2^{\mathrm{a}}$ & $1.4^{\mathrm{a}}$ & $6.8^{\mathrm{a}}$ & $7.7^{d}$ & $43.5^{\mathrm{ab}}$ & $24.8^{\mathrm{a}}$ & $14.6^{\mathrm{a}}$ & $83.1^{\mathrm{a}}$ & $22.6^{\mathrm{a}}$ & $9.1^{\mathrm{e}}$ & $68.3^{\mathrm{a}}$ & $1.71^{\mathrm{a}}$ \\
\hline 16 & $3.4^{\mathrm{a}}$ & $16.6^{\mathrm{a}}$ & $1.6^{\mathrm{a}}$ & $6.6^{\mathrm{a}}$ & $20.3^{c}$ & $46.7^{\mathrm{a}}$ & $4.8^{\mathrm{b}}$ & $18.2^{\mathrm{a}}$ & $78.5^{\mathrm{a}}$ & $26.6^{\mathrm{a}}$ & $21.9^{d}$ & $51.5^{\mathrm{b}}$ & $1.30^{\mathrm{b}}$ \\
\hline 40 & $3.2^{\mathrm{a}}$ & $16.0^{\mathrm{a}}$ & $1.6^{\mathrm{a}}$ & $5.2^{\mathrm{a}}$ & $28.6^{\mathrm{b}}$ & $41.0^{b}$ & $4.4^{b}$ & $17.6^{\mathrm{a}}$ & $79.0^{\mathrm{a}}$ & $24.4^{\mathrm{a}}$ & $30.2^{c}$ & $45.4^{c}$ & $1.26^{b c}$ \\
\hline 80 & $3.1^{\mathrm{a}}$ & $14.2^{\mathrm{a}}$ & $1.2^{\mathrm{a}}$ & $6.3^{\mathrm{a}}$ & $33.4^{\mathrm{a}}$ & $36.2^{c}$ & $5.5^{\mathrm{b}}$ & $15.4^{\mathrm{a}}$ & $81.5^{\mathrm{a}}$ & $23.6^{a}$ & $34.6^{b c}$ & $41.7^{d}$ & $1.24^{c}$ \\
\hline 120 & $4.6^{a}$ & $14.4^{\mathrm{a}}$ & $0.5^{\mathrm{a}}$ & $6.3^{\mathrm{a}}$ & $36.3^{\mathrm{a}}$ & $33.1^{c}$ & $4.8^{b}$ & $15.0^{\mathrm{a}}$ & $80.4^{\mathrm{a}}$ & $25.3^{\mathrm{a}}$ & $36.8^{\mathrm{ab}}$ & $37.9^{e}$ & $1.17^{d}$ \\
\hline 160 & $4.4^{\mathrm{a}}$ & $14.0^{\mathrm{a}}$ & $1.5^{\mathrm{a}}$ & $6.3^{\mathrm{a}}$ & $35.5^{\mathrm{a}}$ & $34.6^{c}$ & $3.8^{\mathrm{b}}$ & $15.4^{\mathrm{a}}$ & $80.1^{\mathrm{a}}$ & $24.7^{\mathrm{a}}$ & $37^{\mathrm{a}}$ & $38.4^{\mathrm{e}}$ & $1.18^{d}$ \\
\hline
\end{tabular}

R. glacialis DBVPG 4785 was cultured at different temperatures in GMY medium containing $40 \mathrm{~g} \mathrm{~L}^{-1}$ glucose. FA within the lipid extract were transformed into the corresponding methyl-esters and were analyzed as described in Methods section. The relative abundance of each FA, the sum of 16- and 18-carbons FA, the sum of the saturated, mono-unsaturated, and poly-unsaturated ones (SFA, MUFA, and PUFA, respectively), and the unsaturation index (UI) are reported as a function initial glucose concentration. The values are means of three independent experiments. Within a column, superscripts indicate statistically similar means, $\mathrm{P}>0.05$, $\mathrm{n}=3$.

it is cultured in a medium with high $\mathrm{C}: \mathrm{N}$ ratio. The fatty acid compositional profile and the content of neutral lipids are quite similar to those of soybean oil and rapeseed oil, indicating that lipids produced by $R$. glacialis DBVPG 4785 have potential as a feedstock for biodiesel production.

Therefore, this yeast could be considered an intriguing microorganism for the production of single cell oils, since it can grow and produce lipids over a wide range of temperatures, although it originates from a cold habitat. Furthermore, the present study is the first proposed biotechnological application for Rhodotorula glacialis species, whose oleaginous biomass accumulates lipids through appropriate cultivation conditions up to $69 \%$ and may find application as novel feedstock for biodiesel production.

\section{Methods}

\section{Strain and culture conditions}

Rhodotorula glacialis DBVPG 4785 was obtained from the Industrial Yeasts Collection DBVPG (University of Perugia, Italy, http://www.agr.unipg.it/dbvpg. The strain was aerobically cultured in GMY medium, which contained $8 \mathrm{~g} \mathrm{~L}^{-1} \mathrm{KH}_{2} \mathrm{PO}_{4}, 0.5 \mathrm{~g} \mathrm{~L}^{-1} \mathrm{MgSO}_{4} 7 \mathrm{H}_{2} \mathrm{O}$, and $3 \mathrm{~g} \mathrm{~L}^{-1}$ yeast extract (Difco Laboratories, Sparks, MD, USA), final pH 5.5 [22]. Glucose was autoclaved separately and supplied at $40 \mathrm{~g} \mathrm{~L}^{-1}$, unless otherwise stated.

\section{Growth experiments and bioreactor operation}

Different glucose concentrations and different temperatures were tried out in bioreactor batch cultures using a Labfors apparatus (Infors AG, Bottmingen, Switzerland) with $2 \mathrm{~L}$ working volume. $R$. glacialis DBVPG 4785 was cultured at $10^{\circ} \mathrm{C}$ in GMY medium containing $1.6,4,8$, $16,40,80,120$, and $160 \mathrm{~g} \mathrm{~L}^{-1}$ glucose, or at $-3,0,5,10$, 15 , and $20^{\circ} \mathrm{C}$ with $40 \mathrm{~g} \mathrm{~L}^{-1}$ glucose. At $-3^{\circ} \mathrm{C}, 30 \mathrm{~g} \mathrm{~L}^{-1}$
$\mathrm{NaCl}$ were supplied to prevent freezing. In any case, the bioreactor was inoculated $(10 \% \mathrm{v} / \mathrm{v})$ with a 48 -h seed culture grown at the target temperature on $4 \mathrm{~g} \mathrm{~L}^{-1}$ glucose. The culture was stirred at $400 \mathrm{rpm}$ and sparged with $0.5 \mathrm{v} / \mathrm{v} / \mathrm{min}$ filter-sterilized air. Samples were collected periodically to monitor the turbidity at $600 \mathrm{~nm}$ and to determine the concentration of cells, biomass, glucose, and lipids.

The cells were counted in a Bürker chamber and biomass dry weight was determined gravimetrically using pre-weighed cellulose nitrate membrane filters. Total cellular carbohydrates were quantified using anthrone reagent [23]. Glucose was analyzed by HPLC equipped with refractive index detector (HPLC System, 1200 Series, Agilent Technologies, Santa Clara, CA). The analysis was performed with an Aminex HPX-87 $\mathrm{H}$ ion exclusion column and $0.005 \mathrm{M} \mathrm{H}_{2} \mathrm{SO}_{4}\left(0.6 \mathrm{ml} \mathrm{min}^{-1}\right)$ as the mobile phase.

\section{Calculation of the specific growth rates, yield coefficients and volumetric productivities}

The specific growth rate $(\mu)$ was calculated using turbidity values in the exponential phase of the growth curve. The weights of biomass, lipids, and consumed glucose were used to calculate biomass/glucose, lipid/glucose, and lipid/biomass yield coefficients $\left(\mathrm{Y}_{\mathrm{X} / \mathrm{S}}, \mathrm{Y}_{\mathrm{L} / \mathrm{S}}\right.$, and $\mathrm{Y}_{\mathrm{L} / \mathrm{X}}$, respectively), expressed as $\mathrm{g} \mathrm{g}^{-1}$. The volumetric productivities of biomass and lipids $\left(\mathrm{Q}_{\mathrm{X}}\right.$ and $\mathrm{Q}_{\mathrm{L}}$, respectively) were calculated by dividing their concentrations with the corresponding culture time.

\section{Lipid analysis}

Biomass from $50 \mathrm{ml}$ culture samples was harvested, washed with distilled water, frozen at $-80^{\circ} \mathrm{C}$ and lyophilized. Lipids were extracted from $1 \mathrm{~g}$ of lyophilized biomass extracted with $50 \mathrm{ml}$ chloroform:methanol mixture [11]. 
Solvents were removed and lipids were determined gravimetrically. To determine the relative composition of fatty acids (FA), the lipids were subjected to methanolysis and the fatty acyl methyl esters were analyzed by GC-MS [11,24]. Quadrupole GC-MS system (HP5890 Series II gas chromatograph-HP5972 mass selective detector) equipped with HP-5 capillary column (Agilent Technologies) and EI ionisation detector $(70 \mathrm{eV})$ was used. The injection temperature was $280^{\circ} \mathrm{C}$ and oven temperature was programmed from $80^{\circ} \mathrm{C}\left(1 \mathrm{~min}\right.$ isotherm) to $130^{\circ} \mathrm{C}$ at a rate of $50^{\circ} \mathrm{C} \mathrm{min}{ }^{-1}$, then to $280^{\circ} \mathrm{C}$ at a rate of $5^{\circ} \mathrm{C} \min ^{-1}(20 \mathrm{~min}$ isotherm at $280^{\circ} \mathrm{C}$ ). The unsaturation index (UI) was calculated as the number of the double bonds of fatty acids multiplied by their relative amount.

\section{Statistical analysis}

All values are means of three separate experiments. Differences in means among the growth temperatures were analyzed using two-way ANOVA with repeated measures with the group as the first factor and temperature as the second factor, followed by Bonferroni post hoc comparisons. Differences were considered statistically significant for $\mathrm{P} \leq 0.05$.

\section{Authors' contributions \\ AA and SR conceived the study, performed the experimental work and drafted the manuscript. MS and LR performed lipid extraction and GC-MS analysis. MDL contributed to the fermentation experiments and chemical analysis. AL accomplished data interpretation and statistical analysis. MR participated in the design of the study and writing of the manuscript. All authors read and approved the final manuscript.}

\section{Competing interests}

The authors declare that they have no competing interests.

Received: 23 July 2010 Accepted: 23 September 2010

Published: 23 September 2010

\section{References}

1. Czabany T, Athenstaedt K, Daum G: Synthesis, storage and degradation of neutral lipids in yeast. Biochim Biophys Acta 2007, 1771:299-309.

2. Daum G, Wagner A, Czabany T, Athenstaedt K: Dynamics of neutral lipid storage and mobilization in yeast. Biochimie 2007, 89:243-248.

3. Antoni D, Zverlov W, Schwarz WH: Biofuels from microbes. Appl Microbiol Biotechnol 2007, 77:23-35

4. Li Q, Du W, Liu D: Perspectives of microbial oils for biodiesel production. Appl Microbiol Biotechnol 2008, 80:749-756.

5. Liu B, Zhao ZK: Biodiesel production by direct methanolysis of oleaginous microbial biomass. J Chem Technol Biotechnol 2007, 82:775-780

6. Ratledge C, Wynn JP: The biochemistry and molecular biology of lipid accumulation in oleaginous microorganisms. Adv Appl Microbiol 2002, 51:1-51

7. Beopoulos A, Cescut J, Haddouche R, Uribelarrea JL, Molina-Jouve C, Nicaud JM: Yarrowia lipolytica as a model for bio-oil production. Prog Lipid Res 2009, 48:375-387.

8. Granger LM, Perlot P, Goma G, Pareilleux A: Efficiency of fatty acid synthesis by oleaginous yeasts: Prediction of yield and fatty acid cell content from consumed $\mathrm{C} / \mathrm{N}$ ratio by a simple method. Biotechnol Bioeng 1993, 42:1151-1156.

9. Rossi M, Buzzini P, Cordisco L, Amaretti A, Sala M, Raimondi S, Ponzoni C, Pagnoni UM, Matteuzzi D: Growth, lipid accumulation, and fatty acids composition in obligate psychrophilic, facultative psychrophilic and mesophilic yeasts. FEMS Microbiol Ecol 2009, 69:363-372.

10. Margesin R, Fonteyne PA, Schinner F, Sampaio JP: Rhodotorula psychrophila sp. nov., Rhodotorula psychrophenolica sp. nov. and Rhodotorula glacialis sp. nov., novel psychrophilic basidiomycetous yeast species isolated from alpine environments. Int I Syst Evol Microbiol 2007, 57:2179-2184.

11. Turchetti B, Buzzini P, Goretti M, Branda E, Diolaiuti G, D'Agata C, Smiraglia C, Vaughan-Martini A: Psychrophilic yeasts in glacial environments of Alpine glaciers. FEMS Microbiol Ecol 2008, 63:73-83.

12. Cavicchioli R, Tortsen T: Extremophiles. Encyclopedia of Microbiology Lederberg, Academic Press, San Diego, second 2000, 317-337.

13. Margesin R: Effect of temperature on growth parameters of psychrophilic bacteria and yeasts. Extremophiles 2009, 13:257-262.

14. Ratledge C: Fatty acid biosynthesis in microorganisms being used for Single Cell Oil production. Biochimie 2004, 86:807-815.

15. Rodríguez-Vargas S, Sánchez-García A, Martínez-Rivas JM, Prieto JA, RandezGil F: Fluidization of membrane lipids enhances the tolerance of Saccharomyces cerevisiae to freezing and salt stress. Appl Environ Microbiol 2007, 73:110-116.

16. Turk M, Montiel V, Zigon D, Plemenitas A, Ramos J: Plasma membrane composition of Debaryomyces hansenii adapts to changes in $\mathrm{pH}$ and external salinity. Microbiology 2007, 153:3586-3592.

17. Gangar A, Raychaudhuri S, Rajasekharan R: Alteration in the cytosolic triacylglycerol biosynthetic machinery leads to decreased cell growth and triacylglycerol synthesis in oleaginous yeast. Biochem J 2002, 365:577-589.

18. Ratledge $C$ : Regulation of lipid accumulation in oleaginous microorganisms. Biochem Soc Trans 2002, 30:1047-1050.

19. Satyarthi JK, Srinivas D, Ratnasamy P: Estimation of Free Fatty Acid Content in Oils, Fats, and Biodiesel by ${ }^{1} \mathrm{H}$ NMR Spectroscopy. Energy Fuels 2009, 23:2273-2277.

20. Granger LM, Perlot P, Goma G, Pareilleux A: Kinetics of growth and fatty acid production of Rhodotorula glutinis. Appl Microbiol Biotechnol 1992, 36:13-17.

21. Koike Y, Cai HJ, Higashiyama K, Fujikawa S, Park EY: Effects of consumed carbon to nitrogen ratio on mycelia morphology and arachidonic acid production in cultures of Mortierella alpina. J Biosc Bioeng 2001, 91:382-389.

22. Buzzini P: Batch and fed-batch carotenoid production by Rhodotorula glutinis-Debaryomyces castellii co-cultures in corn syrup. J App/ Microbiol 2001, 90:843-847.

23. Trevelyan WE: Determination of Yeast Carbohydrates with the Anthrone Reagent. Nature 1952, 170:626-627.

24. Morrison WR, Smith LM: Preparation of fatty acid methyl esters and dimethyl acetals from lipids with boron fluoride methanol. J Lipid Res 1964, 5:600-608.

doi:10.1186/1475-2859-9-73

Cite this article as: Amaretti et al: Single cell oils of the cold-adapted oleaginous yeast Rhodotorula glacialis DBVPG 4785. Microbial Cell Factories 2010 9:73.

\section{Submit your next manuscript to BioMed Central and take full advantage of:}

- Convenient online submission

- Thorough peer review

- No space constraints or color figure charges

- Immediate publication on acceptance

- Inclusion in PubMed, CAS, Scopus and Google Scholar

- Research which is freely available for redistribution 